\title{
Learning From Failure in an MBA Oral Presentation Course
}

\author{
Mari Nishitani \\ Hitotsubashi University, Tokyo, Japan
}

\begin{abstract}
The primary aim of this study was to examine the hypothesis that integrating teaching about learning from failure into a course would lead to positive changes in perceptions of failure and use of strategies for learning from failure, while the secondary aim was to clarify learners' opinions regarding the use of corporate studies as material for oral presentations. The study suggests that perceptions of failure become more positive through teaching about learning from failure. Post-course surveys of the experimental group clearly show that perceptions of anxiety had become significantly more positive. Furthermore, the open-ended responses suggest that students had acquired strategies for learning from failure. Accordingly, it seems that teaching about learning from failure was effective. Regarding the secondary aim, as far as selecting corporate studies as materials for presentations was concerned, results showed that this raised student interest, and that levels of satisfaction were high, suggesting that effectiveness extended beyond simply practicing oral presentations.
\end{abstract}

Keywords: Master of Business Administration (MBA) courses, oral presentations, failure, anxiety, corporate studies

\section{Introduction}

A Master of Business Administration (MBA) course has been established in Hitotsubashi University Graduate School of Commerce and Management. The university Website states:

We proactively engage with the globalization of business. From the 2012 academic year, a program for international students was established, admitting outstanding students from other countries, while actively promoting opportunities for Japanese students and international students to interact. After a special selection process, international students spend the first semester of their first year taking intensive courses in Japanese and topics related to Japanese industry and culture, before joining regular students from the second semester of their first year and progressing to full-scale MBA study. Over the two-year period, they acquire a high level of Japanese proficiency and management skills appropriate to work at the front line of business. (Hitotsubashi University, n.d.)

The focus of this paper is on the foreign students admitted to this international student program, which began in the 2012 academic year. During each week of the first semester of the first year, students in the international student program take eight 90-minute advanced, specialized Japanese language classes. The content of classes is listed below, and the author teaches oral presentation:

(a) Listening comprehension: Television listening;

(b) Reading comprehension: Extensive reading;

(c) Sentence patterns/expressions: Basic expressions;

(d) Oral presentation: Presentations using corporate studies as materials;

(e) Written expressions: Guidance on report writing;

Mari Nishitani, Ph.D., professor, Department of Center for Global Education, Hitotsubashi University. 
(f) Text reading 1: Post-war Japanese economic history;

(g) Text reading 2: Corporate finance;

(h) Text reading 3: Competitive strategy theory and organizational design.

\section{Teaching to Learn From Failure}

The author has previously engaged in research on anxiety and failure among learners of the Japanese language (Nishitani \& Matsuda, 2011). This research showed that learners with high intrinsic motivation perceive failure positively, understand the usefulness of failure, are able to use a wide range of learning strategies, and in particular, tend to use the strategy of learning from failure by "learning what is right from other people's mistakes" and "correcting mistakes and trying not to make the same mistake again” (see Figure 1). The key to teaching learning strategies is promoting the strategy with the highest correlation between being able to recognize the benefits of failure and being able to learn from failure.

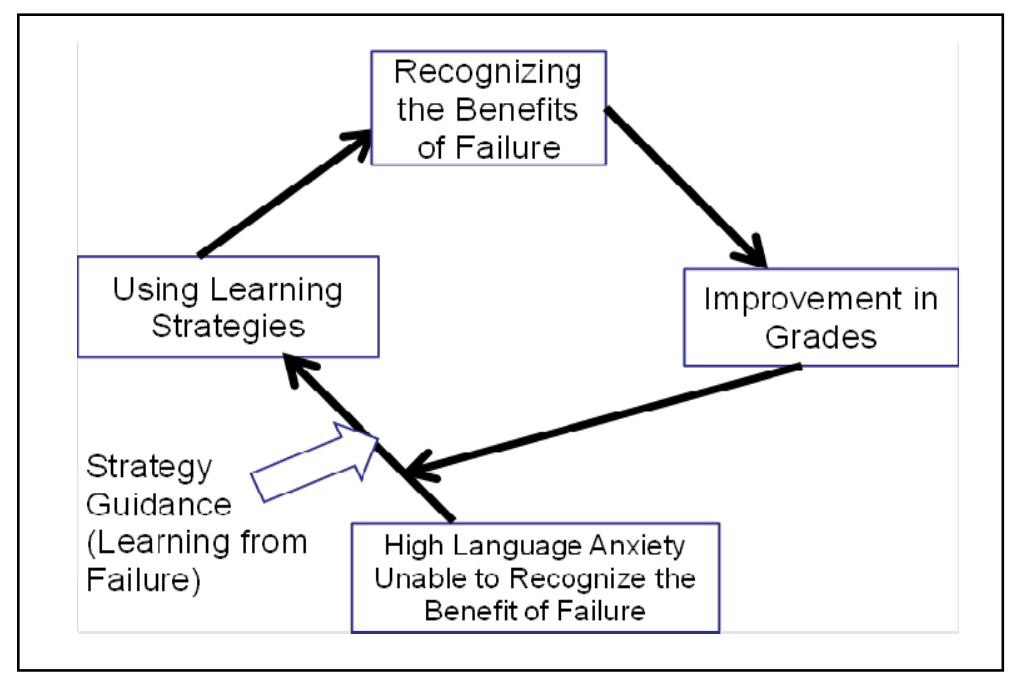

Figure 1. A model showing how strategy use leads to the improvement of language performance.

Ikeda and Mizawa (2012) showed that learners’ beliefs about failure determined their casual attributions for negative events and their subsequent coping behavior, and they have emphasized the necessity of minimizing the negative effects possessed by the failure.

The author also conducted a workshop for Japanese teachers of the Japanese language in Vietnam, the purpose of which was to teach strategies for learning from failure by discussing changes in awareness of failure (Nishitani, 2014). While there were no statistically significant differences in understanding of the usefulness of failure before and after the workshop, responses to open questions in the post-workshop survey revealed opinions regarding raised consciousness of failure and making use of this, not being afraid of failure, and sharing failure with colleagues.

For this study, the perspective of learning from failure was integrated into plans for a course teaching oral expressions to advanced learners' of Japanese in an MBA course. By developing more positive perceptions of failure using strategies for learning from failure, the author believes that students will gain the capability to develop autonomously, not only in oral presentations, but also in terms of the aim of the special international student program, which is to "acquire a high level of Japanese proficiency and management skills appropriate to work at the front line of business." 
This paper examines the hypothesis that integrating teaching about learning from failure into a course will enable students to positively modify their perceptions of failure, and use strategies to learn from failure. The study also clarifies learners' awareness regarding the use of corporate studies as material for oral presentation.

\section{Overview of Students}

A total of 20 students entered the international student program in the 2015 academic year. These students were split into two classes for the course. Groups were divided so that there was no bias in terms of students' nationalities, sex, work experience, or field of undergraduate study. Before the course began, the students took a reading test of frequently occurring four-character kanji (Chinese characters) words in the field of economics and commerce, worth 100 points, as well as a 10-minute interview for pronunciation, fluency, and accuracy (scored by two faculty members on a scale of 40 points, total 80 point), and a 5-point scale pre-course survey related to presentation anxiety, perceptions of anxiety, and intrinsic motivation (see Appendix).

As is clear from Table 1, the majority of students came from countries where kanji are used, and only three students from Vietnam and Mongolia came from countries where kanji are not used. Another feature is that females constituted $80 \%$ of the group. Over half of the students graduated from Japanese language undergraduate programs. Overall, presentation anxiety was moderate, while intrinsic motivation was high, and many students perceived failure positively.

Table 1

Overview of Students

\begin{tabular}{|c|c|c|c|}
\hline & & Group 1 & Group 2 \\
\hline \multirow{5}{*}{ Nationality } & Chinese & 7 & 7 \\
\hline & Taiwanese & 1 & 1 \\
\hline & Korean & 1 & - \\
\hline & Vietnamese & 1 & 1 \\
\hline & Mongolian & - & 1 \\
\hline \multirow{2}{*}{ Sex } & Female & 8 & 8 \\
\hline & Male & 2 & 2 \\
\hline \multirow{2}{*}{ Career } & Yes & 6 & 6 \\
\hline & No & 4 & 4 \\
\hline \multirow{3}{*}{ Undergraduate } & Japanese & 5 & 6 \\
\hline & Management & 3 & 2 \\
\hline & Others & 2 & 2 \\
\hline \multicolumn{2}{|c|}{ Kanji test (Total score $=100)$} & $87.00(S D=12.24)$ & $91.60(S D=6.15)$ \\
\hline \multicolumn{2}{|c|}{ Conversation test $($ Total score $=80$ ) } & $58.00(S D=12.86)$ & $60.80(S D=12.48)$ \\
\hline \multicolumn{2}{|l|}{ Total score } & $145.0(S D=22.93)$ & $152.4(S D=16.22)$ \\
\hline \multicolumn{2}{|c|}{ Presentation anxiety } & $3.15(S D=0.73)$ & $2.78(S D=1.06)$ \\
\hline \multicolumn{2}{|c|}{ Perceptions of failure } & $4.20(S D=0.63)$ & $3.90(S D=1.08)$ \\
\hline \multicolumn{2}{|c|}{ Intrinsic motivation factors } & $4.75(S D=0.27)$ & $4.80(S D=0.25)$ \\
\hline
\end{tabular}

In the pre-course test and pre-course survey conducted before the beginning of the intensive Japanese language class, there were no significant differences between the two groups on the $t$-test. In other words, the two groups were almost equal in terms of Japanese language ability, anxiety about presentations, perceptions of anxiety, and intrinsic motivation. In order to examine the effectiveness of teaching how to learn from failure, 
Group 1 was the experimental group, which received teaching about learning from failure, while Group 2 was the control group, which did not receive teaching about learning from failure. However, in order to avoid unfair treatment, materials related to failure distributed to Group 1 (the experimental group) were distributed to Group 2 after the post-course survey in the last class.

\section{Overview of the Course}

Almost all international students in the MBA course aimed to work in Japan after graduation. In parallel with the intensive Japanese language class, they also took seminars to learn about issues, such as Japanese corporate culture and specialist subjects in management. For these reasons, to maximize the knowledge obtained in specialist subjects and as useful resources for future job-hunting activities, oral presentation content focused on corporate studies.

In the first class, a lecture on techniques for oral presentation was given to both groups. This included issues, such as "paying attention to conceptual stages," "how to create PowerPoint slides," and "copyright precautions.” Procedures for presentations required the students to send an outline of their presentation by e-mail to the author by three days before the presentation. Content and structure were then discussed by the student and author together, and the student prepared PowerPoint presentation materials by the day of the presentation. The other students listened to each presentation and then evaluated the student's way of speaking, content, structure, and comprehensibility of the slides and handouts on a 4-point scale. The final stage of the procedure was for students' evaluation and the author's feedback to be given to the presenting student.

Corporate studies were done in three parts. Part 1 was a 15-minute presentation with reference to a Japanese corporation selected by the author from 2014 economics magazines. Same corporation was used for Group 1 and Group 2. Part 2 was a 20-minute presentation about a corporation in the student's home country, selected by the student. Finally, Part 3 was a 25-minute presentation on a company in the student's home country, Japan or another country, selected by the student.

\section{Teaching About Learning From Failure}

Lectures on oral presentation techniques and common Japanese errors were provided to both Group 1 and Group 2 in the first class of the course, and at the end of Part 1 and Part 2. In addition to this, lectures on how to perceive failure were given to Group 1 (the experimental group) and in feedback from the teacher after oral presentations for this group, students were made aware of their mistakes and received written encouragement.

In the first class with Group 1 (the experimental group), students were told about "what can be learned from their own mistakes," "what can be learned from others' mistakes," and "sharing blunders," as well as the fact that "there are good failures and bad failures." After the oral presentations in Part 1, a lecture on the theme of "no development without failure" and "effective methods for learning from failure” was given, based on Hatamura's (2014) Knowledge of Failure. After finishing Part 2, in the same way, a lecture and discussion on the theme of "ways of recovering from failure” was conducted, also based on Hatamura's (2014) Knowledge of Failure.

\section{Effectiveness of Teaching About Learning From Failure}

As one student from the experimental group of 10 withdrew from all intensive Japanese language classes, the post-course survey was administered to 19 students. The post-course survey comprised the same items as 
the pre-course survey, covering presentation anxiety and perceptions of anxiety, together with the following open-ended questions: "What have you learned from the failures and successes of your classmates and yourself?" and "What do you think about using corporate studies as material for presentation content?"

Mean scores for presentation anxiety and perceptions of anxiety in the pre-course and post-course survey are shown in Table 2. In Table 2, differences in figures for the pre-course survey for Group 1 are due to recalculations after removing the data of the student who withdrew from the post-course survey.

In the post-course survey, Group 1 (the experimental group) and Group 2 (the control group) showed the same scores for presentation anxiety, but while presentation anxiety scores for Group 1 (the experimental group) fell, there were no changes in scores for Group 2 (the control group). Group 1, which had been taught about learning from failure, showed higher scores for perceptions of anxiety than Group 2, which did not receiving teaching about learning from failure, and were more positive in their perceptions of anxiety, but the $t$-test showed no significant differences. In addition, no significant differences were observed between the two groups in any item of presentation anxiety or perception of anxiety.

Table 2

Changes in Anxiety and Perceptions of Failure (Mean Scores)

\begin{tabular}{lllllll}
\hline & & \multicolumn{2}{c}{ Group 1 (The experimental group) } & & \multicolumn{2}{c}{ Group 2 (The control group) } \\
\cline { 3 - 4 } & & $M$ & $S D$ & & $M$ & $S D$ \\
\hline \multirow{2}{*}{ Presentation anxiety } & Before & 3.19 & 0.76 & 2.78 & 1.06 \\
& After & 2.78 & 0.82 & 2.78 & 0.90 \\
\hline \multirow{2}{*}{ Perceptions of failure } & Before & 3.94 & 0.65 & 3.90 & 0.80 \\
& After & 4.36 & 0.53 & 4.06 & 0.72 \\
\hline
\end{tabular}

On the other hand, on the paired $t$-test, Group 1 (the experimental group) mean score for perceptions of anxiety rose from 3.94 to $4.36(t=2.42 ; p=0.042)$. That is to say, perceptions of anxiety became significantly positive. Significant changes in each item of presentation anxiety and perceptions of anxiety for Group 1 (the experimental group) are shown in Table 3. Changes in scores for "I think that other people's failures are useful for me, and my failures are useful for other people” were large. For Group 2 (the control group), there were no significant changes in any item of presentation anxiety or perceptions of anxiety.

Table 3

Changes in Anxiety and Perceptions of Failure in Group 1 (the Experimental Group)

\begin{tabular}{|c|c|c|c|c|c|c|}
\hline & \multicolumn{2}{|c|}{ Before } & \multicolumn{2}{|c|}{ After } & & \multirow{2}{*}{$p$} \\
\hline & $M$ & $S D$ & $M$ & $S D$ & & \\
\hline $\begin{array}{l}\text { I am anxious about presenting my own opinions } \\
\text { in front of other people. }\end{array}$ & 3.44 & 1.01 & 2.56 & 1.23 & 2.10 & 0.069 \\
\hline $\begin{array}{l}\text { I think that failing in ordinary situations leads to } \\
\text { not failing in important situations. }\end{array}$ & 3.88 & 0.99 & 4.33 & 1.12 & -2.38 & 0.049 \\
\hline $\begin{array}{l}\text { I think that other people's failures are useful for } \\
\text { me, and my failures are useful for other people. }\end{array}$ & 4.11 & 0.60 & 4.78 & 0.44 & -4.00 & 0.004 \\
\hline
\end{tabular}

Oral presentation grades were decided by the author's evaluation (75 points) and student peer evaluations (25 points). The mean score for Group 1 (the experimental group) was 84.4 points, which was slightly higher than the mean score for Group 2 (the control group), which was 82.3 points, but there were no significant differences in scores between the two groups. Overall correlation coefficients for grades and presentation 
anxiety and perceptions of anxiety were calculated, but no significant positive or negative correlation was apparent for any item.

In reply to the question, "What have you learned from the failures and successes of your classmates and yourself?” There were responses from Group 1 (the experimental group), on learning from their own failures. Several examples are shown below:

I was too nervous for the first presentation and so it was a failure, but after practicing many times, the stress went away. I learned to get rid of the nervousness by practicing again and again.

I thought there was no problem myself, but I learned that other people thought there was a problem.

In contrast, responses from Group 2 (the control group) focused on learning technical aspects of presentations, such as how to use PowerPoint, looking at listeners when speaking, and tips for communicating information, and there were no responses on learning from failure. This suggests that students from Group 1 (the experimental group) acquired strategies for learning from failure, unlike students from Group 2 (the control group).

\section{Significance of Using Corporate Studies for Oral Presentations}

All learners responded that using corporate studies as materials for oral presentations was "an appropriate and useful theme for MBA students.” Several responses are shown below:

I was satisfied as we could find out about various interesting companies. That will be useful when it comes to job hunting.

I have managed to get an image of companies I was not interested in before now. I understand what I need to find out about companies.

I have started to understand a little about companies in the home countries of my classmates.

This has been a good introduction to what we will be studying after this, as well as honing our presentation skills.

Reasons for seeing corporate studies as appropriate and useful material can be summarized into the following two points:

1. Students could find out about companies that they had not previously been interested in, and various companies in Japan and abroad;

2. The material, including specialist knowledge, would be useful for future studies and job-hunting activities.

\section{Conclusion and Future Issues}

The primary aim of this study was to test the hypothesis that integrating teaching about learning from failure into a course would lead to positive changes in perceptions of failure and use of strategies for learning from failure, while the secondary aim was to clarify learners' opinions regarding the use of corporate studies as material for oral presentations.

Regarding the primary aim, the study suggests that perceptions of failure become more positive through teaching about learning from failure. While there were no significant differences in mean scores when comparing Group 1 (the experimental group) with Group 2 (the control group) comparison of the pre-course and post-course surveys of Group 1 (the experimental group) clearly shows that perceptions of anxiety had become significantly more positive. Furthermore, the open-ended responses suggest that students had acquired strategies for learning from failure. Accordingly, it seems that teaching about learning from failure was 
effective. There were no significant differences between the two groups in oral presentation grades, but given that this course aimed to integrate the perspective of learning from failure, perceiving failure positively, and using strategies to learn from failure, to autonomously develop "a high level of Japanese proficiency and management skills appropriate to work at the front line of business," it can be said that results were obtained to a certain extent.

Regarding the secondary aim, as far as selecting corporate studies as materials for presentations was concerned, results showed that this raised student interest, and that levels of satisfaction were high, suggesting that effectiveness extended beyond simply practicing oral presentations. On the other hand, there was also the opinion from students that "The scope of selection of companies was too wide. It would be better to narrow the scope to some extent to certain industry types or the latest topics of debate." How to use this to maximum benefit in future course design is an issue for further investigation.

\section{References}

Hatamura, Y. (2014). Knowledge of failure. Kadokawa Chukei Press. (In Japanese)

Hitotsubashi University. (n.d.). Retrieved July 2, 2015, from http://www.mba.cm.hit-u.ac.jp/about/philosophy/

Ikeda, H., \& Mizawa, R. (2012). Conceptualization and measurement of beliefs about failure. The Japanese Journal of Educational Psychology, 60(4), 367-379

Nishitani, M. (2014). Practice of workshop to learn from failure (Research Report of Jest Conference, JEST12-5, pp. 179-184). (In Japanese)

Nishitani, M., \& Matsuda, T. (2011). The relationship between language anxiety, interpretation of anxiety, intrinsic motivation and the use of learning strategies. US-China Education Review B, 8(9), 438-446. 
Appendix: Pre- and Post- Course Survey Items

\section{Presentation Anxiety}

1. I am anxious about presenting my own opinions in front of other people.

2. I think other people can speak more fluently than I can.

3. I often get confused in my ideas when I am speaking in front of others.

4. I am anxious that other people might misjudge me or have a bad impression of me, because I cannot express what I want to say properly.

\section{Perceptions of Failure}

5. I think that failing in ordinary situations leads to not failing in important situations.

6. Failing stays in my memory, and so I do not fail the next time.

7. If someone points out my mistakes, I can understand things that were vague before more clearly.

8. Nobody is perfect from the very beginning, so I think it is normal to fail at first.

9. I think that other people's failures are useful for me, and my failures are useful for other people.

\section{Intrinsic Motivation Factors}

10. It is fun gaining new knowledge from studying.

11. I wish to develop myself into a more complete person by learning new things.

12. I want to do my best even when studying a difficult subject.

13. I always do my best in any field of study that I undertake.

14. I put in effort studying or working, because I enjoy it.

15. When studying, I always have a goal in mind. 